\title{
Effects of Brassinosteroid on growth, development, yield and activities of some antioxidant enzymes of Jasmine 85 rice cultivar under salinity conditions
}

\author{
Van H. Phan $^{1 *}$, Tri M. Bui ${ }^{1}$, \& Sanh D. Nguyen ${ }^{2}$ \\ ${ }^{1}$ Faculty of Agronomy, Nong Lam University, Ho Chi Minh City, Vietnam \\ ${ }^{2}$ Faculty of Biology, University of Science, Ho Chi Minh City, Vietnam
}

\begin{abstract}
ARTICLE INFO
Research Paper

Received: August 15, 2020

Revised: September 27, 2020

Accepted: October 19, 2020

Keywords

Antioxidant enzymes

Brassinosteroid

Jasmine 85

Salinity

${ }^{*}$ Corresponding author

Phan Hai Van

Email: phvan@hcmuaf.edu.vn
\end{abstract}

\begin{abstract}
The objective of the experiment was to determine effects of Brassinosteroid (BRs) concentrations on growth, development and yield of Jasmine 85 rice cultivar under salinity conditions at panicle initiation stage. The experiment was laid out in a completely randomized design with three replications and consisted of two factors. The first factor comprised three salinity concentrations: $0 \%$ (control), $2 \%$ and $4 \%$ and the second factor had three concentrations of BRs: $0 \mathrm{ppm}$ (control), $2 \mathrm{ppm}$ and $4 \mathrm{ppm}$. The results showed that under non-saline conditions, the control rice plants sprayed with BRs at a concentration of $2 \mathrm{ppm}$ had the highest values of root length $(33.39 \mathrm{~cm})$, leaf area $\left(42.41 \mathrm{~cm}^{2}\right)$, proportion of firm seeds $(72.20 \%)$, weight of 1000 seeds $(28.14 \mathrm{~g})$ and yield $(725.55$ $\mathrm{g} / \mathrm{barrel})$. At the salinity level of $4 \%$, rice plants sprayed with BRs at a concentration of $2 \mathrm{ppm}$ demonstrated the highest levels of APX and CAT enzymes. Briefly, rice plants grown under higher salinity levels had decreased growth and yield. Spraying BRs helped improve growth and yield parameters of rice under high salinity conditions.
\end{abstract}

Cited as: Phan, V. H., Bui, T. M., \& Nguyen, S. D. (2020). Effects of Brassinosteroid on growth, development, yield and activities of some antioxidant enzymes of Jasmine 85 rice cultivar under salinity conditions. The Journal of Agriculture and Development 19(5), 27-34. 


\title{
Ảnh hưởng của Brassinosteroid lên sự sinh trưởng, phát triển, năng suất và hoạt tính một số enzyme chống oxy hóa của giống lúa Jasmine 85 trong điều kiện mặn
}

\author{
Phan Hải Văn ${ }^{1 *}$, Bùi Minh Trí ${ }^{1} \&$ Nguyễn Du Sanh ${ }^{2}$ \\ ${ }^{1}$ Khoa Nông Học, Trường Đại Học Nông Lâm TP.HCM, TP. Hồ Chí Minh \\ ${ }^{2}$ Khoa Sinh Học, Trường Đại Học Khoa Học Tự Nhiên TP.HCM, TP. Hồ Chí Minh
}

\author{
THÔNG TIN BÀI BÁO \\ Bài báo khoa học \\ Ngày nhận: 15/08/2020 \\ Ngày chỉnh sửa: $27 / 09 / 2020$ \\ Ngày chấp nhận: 19/10/2020 \\ Từ khóa \\ Brassinosteroid \\ Enzyme chống oxy hóa \\ Giống lúa Jasmine 85 \\ Mặn \\ *Tác giả liên hệ \\ Phan Hải Văn \\ Email: phvan@hcmuaf.edu.vn
}

\section{TÓM TẮT}

Mục tiêu của nghiên cứu nhằm xác định ảnh hưởng của nồng độ Brassinosteroid (BRs) đến sinh trưởng, phát triển và năng suất trong điều kiện nhiễm mặn ở giai đoạn làm đòng. Thí nghiệm được bố trí theo kiểu hoàn toàn ngẫu nhiên với ba lần lặp lại và gồm có hai yếu tố. Yếu tố thứ nhất gồm ba nồng độ xử lý mặn: ( $0 \%$ o (đối chứng), $2 \%$ o, 4\%o) và yếu tố thứ hai gồm ba nồng độ BRs: 0 ppm (đối chứng), 2 ppm, 4 ppm. Trong điều kiện không xử lý mặn, cây lúa được phun BRs ở nồng độ $2 \mathrm{ppm}$ có chiều dài rễ $(33,39 \mathrm{~cm})$, diện tích lá đòng $\left(42,41 \mathrm{~cm}^{2}\right)$, tỷ lệ hạt chắc $(72,20 \%)$, trọng lượng 1000 hạt $(28,14 \mathrm{~g})$, năng suất $(725,55$ $\mathrm{g} /$ thùng) cao nhất. Khi xử lý mặn ở nồng độ 4\%o, cây lúa được phun BRs ở nồng độ 2 ppm có hoạt độ enzyme APX và CAT cao nhất. Tóm lại, cây lúa được trồng ở điều kiện độ mặn cao thì sinh trưởng và năng suất giảm. Phun BRs giúp cải thiện các chỉ tiêu về sinh trưởng và năng suất của cây lúa trong điều kiện độ mặn cao.

\section{1. Đặt Vấn Đề}

Ở Việt Nam, lúa gạo chiếm vị trí vô cùng quan trọng trong nền kinh tế quốc dân, lúa gạo không chỉ là nguồn cung cấp lương thực chính mà còn là mặt hàng xuất khẩu quan trọng. Tuy nhiên, trong những năm gần đây, do ảnh hưởng của biến đổi khí hậu đã làm giảm diện tích đất trồng lúa, ảnh hưởng không nhỏ đến sản lượng và năng suất ngành trồng lúa. Đặc biệt là các giống gạo thơm xuất khẩu, các giống này bị ảnh hưởng nhiều hơn so với các giống thông thường trong đó có giống Jasmine 85.

Trước ảnh hưởng nghiêm trọng của mặn thì việc chọn giống lúa chống chịu mặn có chất lượng và năng suất cao sẽ đòi hỏi thời gian kéo dài hàng chục năm, vì vậy việc bổ sung ngoại sinh các chất điều hòa sinh trưởng thực vật để tăng cường khả năng chịu mặn của cây trồng là biện pháp đáng để lựa chọn. Trên thế giới và Việt Nam đã có nhiều nghiên cứu về việc bổ sung các chất điều hòa sinh trưởng thực vật ngoại sinh nhằm tăng cường tính chống chịu ở thực vật. Trong nhóm chất điều hòa sinh trưởng thực vật thì Brassinosteroid (BRs) đang được nhiều nhà nghiên cứu trong và ngoài nước quan tâm.

Brassinosteroid là một nhóm các chất điều hòa sinh trưởng thực vật có vai trò then chốt trong một loạt các hiện tượng phát triển ở thực vật bao gồm phân chia tế bào và kéo dài tế bào ở thân và rễ, phát sinh tế bào, phát triển sinh sản, lão hóa lá và phản ứng với điều kiện bất lợi (Clouse \& Sasse, 1998). Trên thế giới có một số nghiên cứu về ảnh hưởng của BRs như xử lý hạt giống với dung dịch BRs loãng đã cải thiện một cách đáng kể sự sinh trưởng của các cây họ lúa trong điều kiện mặn. Ở Việt Nam, Nguyen (2018) đã nghiên cứu về tác động của BRs đến lúa trong điều kiện mặn như phun BRs giúp cải thiện hiệu quả sinh trưởng cây lúa nhờ duy trì tốt số bông $/ \mathrm{m}^{2}$, số hạt chắc/bông dẫn đến gia tăng năng suất lúa. Chính vì vậy, mục tiêu của nghiên cứu nhằm xác định ảnh hưởng của 
nồng độ Brassinosteroid (BRs) đến sinh trưởng, phát triển và năng suất trong điều kiện nhiễm mặn ở giai đoạn làm đòng.

\section{Vật Liệu và Phương Pháp Nghiên Cứu}

\subsection{Vật liệu}

Giống lúa Jasmine 85 do Công ty Cổ phần Tập đoàn Lộc Trời cung cấp. Giống lúa này có đặc điểm như sau: thời gian sinh trưởng từ $95-102$ ngày; chiều cao cây $85-90 \mathrm{~cm}$, đẻ nhánh trung bình, lá đòng thẳng; khối lượng 1,000 hạt khoảng $26-27$ g. Hạt gạo dài $7,2-7,6 \mathrm{~mm}$, trong suốt, không bạc bụng, hàm lượng amylose trung bình $(20-21 \%)$, độ hóa hồ cấp 5 , cơm mềm, dẻo, có mùi thơm đặc trưng. Giống Jasmine 85 chịu mặn, chịu hạn kém.

\subsection{Bố trí thí nghiệm}

Thí nghiệm được bố trí theo kiểu hoàn toàn ngẫu nghiên với ba lần lặp lại. Yếu tố thứ nhất gồm ba nồng độ mặn: 0 (Đối chứng), $3 \%$ và $4 \%$; yếu tố thứ hai gồm 3 nồng độ BRs: 0 (Đối chứng), 2 và $4 \mathrm{ppm}$. Lúa được trồng trong các thùng xốp $(60 \times 40 \times 30 \mathrm{~cm})$. Tổng số thùng được sử dụng trong thí nghiệm là 108 thùng.

\subsection{Các bước thực hiện thí nghiệm}

Việc xử lý mặn được thực hiện trong giai đoạn làm đòng 37 - 43 ngày sau gieo (NSG) với các nồng độ muối $0 \%$, $3 \%$ và $4 \%$. Brassinolide (dẫn xuất của $\mathrm{BRs}$ ) được phun với nồng độ lần lượt là 0,2 và $4 \mathrm{ppm}$ vào ngày thứ 5 sau khi xử lý mặn theo từng nghiệm thức thí nghiệm. Đến thời điểm $43 \mathrm{NSG}$, tiến hành rửa mặn bằng cách hút hết nước muối ra khỏi thùng sau đó thay bằng nước tưới bình thường.

Thí nghiệm được bón phân theo công thức 100 $\mathrm{kg} \mathrm{N} / \mathrm{ha}-40 \mathrm{~kg} \mathrm{P}_{2} \mathrm{O}_{5} / \mathrm{ha}-30 \mathrm{~kg} \mathrm{K2O} /$ ha với lượng bón được chia theo 3 đợt: Đợt 1: 1/2 phân đạm + 1/2 kali (7 NSG); Đợt 2: 1/3 phân đạm + 1/2 phân kali (22 NSG); Đợt 3: 1/3 phân đạm (40 NSG).

\subsection{Các chỉ tiêu theo dõi}

Các chỉ tiêu theo dõi về sinh trưởng, phát triển và năng suất bao gồm: Chiều cao cây $(\mathrm{cm})$, diện tích lá đòng $\left(\mathrm{cm}^{2} /\right.$ lá $)$, chiều dài rễ $(\mathrm{cm})$, tổng số hạt trên cây (hạt/cây), trọng lượng 1000 hạt (g), tỷ lệ hạt chắc (\%) và năng suất (g/thùng). Chỉ tiêu sinh hóa bao gồm: Hàm lượng proline (mg/g): đo mật độ quang ở bước sóng $520 \mathrm{~nm}$ bằng máy đo mật độ quang (Paquin \& Lechasseur, 1979); Hàm lượng protein ( $\mathrm{\mu g} / \mathrm{g})$ : đo mật độ quang ở bước sóng $595 \mathrm{~nm}$ bằng máy đo mật độ quang (Bradford, 1976); Hoạt độ enzyme catalase (CAT) (EC.1.11.1.6) được xác định theo Chance \& Maehly (1955); Hoạt độ enzyme ascorbate peroxidase (APX) (EC.1.11.1.11) được xác định theo Nakano \& Asada (1981).

Số liệu được thống kê và tính trung bình bằng phần mềm Excel, trắc nghiệm phân hạng ANOVA bằng phần mềm SAS 9.1.

\section{Kết Quả và Thảo Luận}

Kết quả Bảng 1 cho thấy, khi được phun BRs ở các nồng độ khác nhau thì chiều cao cây lúa có sự khác biệt rất có ý nghĩa thống kê ở các nồng độ mặn khác nhau. Cây lúa được xử lý mặn ở nồng độ $4 \%$ có chiều cao cây thấp nhất $(91,07 \mathrm{~cm})$, khác biệt rất có ý nghĩa thống kê so với ở nồng độ $2 \%$ và không xử lý mặn (đối chứng). Điều này cho thấy nồng độ mặn trong nước càng cao thì chiều cao cây lúa càng giảm. Kết quả này phù hợp với kết quả của Saxena \& Pandey (1981) khi họ cho rằng chiều cao cây giảm một cách tuyến tính với việc gia tăng mức độ mặn. Hasanuzzaman \& ctv. (2009) cũng đã cho thấy ảnh hưởng của độ mặn lên chiều cao cây ở các giống khác nhau có thể do khả năng di truyền của giống. Việc phun BRs giúp cây lúa tăng trưởng chiều cao đáng kể trong điều kiện xử lý mặn. Cây lúa Jasmine 85 cao nhất khi được phun BRs ở nồng độ 4 ppm (95,03 cm), không khác biệt thống kê so với khi được phun ở nồng độ 2 ppm, nhưng khác biệt rất có ý nghĩa thống kê so với đối chứng 0 ppm $(91,44$ $\mathrm{cm})$. Brassinosteroid là hoocmon thực vật có liên quan đến việc thúc đẩy tăng trưởng và phát triển của cây. Một trong những ảnh hưởng thú vị nhất của BRs là khả năng giúp thực vật chống lại các stress phi sinh học khác nhau (Bajguz \& Hayat 2009; Hayat \& ctv., 2010).

Diện tích lá đòng của giống lúa Jasmine 85 bị ảnh hưởng bởi các nồng độ mặn, BRs và tương tác giữa hai yếu tố này (Bảng 1 ). Diện tích lá đòng của cây lúa đạt cao nhất khi không được xử lý mặn $\left(41,68 \mathrm{~cm}^{2}\right)$, khác biệt rất có ý nghĩa thống kê so với ở nồng độ $3 \%$ và $4 \%$. Như vậy, nồng độ mặn trong nước tưới ảnh hưởng rõ rệt đến diện tích lá đòng của cây lúa. Ở các nồng độ mặn khác 
Bảng 1. Ảnh hưởng của nồng độ Brassinosteroid (BRs) đến chiều dài rễ, chiều cao cây và diện tích lá đòng của giống lúa Jasmine 85

\begin{tabular}{|c|c|c|c|c|c|}
\hline \multirow{2}{*}{ Ngày xử lý } & \multirow{2}{*}{$\begin{array}{c}\text { Độ mặn (\%o) } \\
(\mathrm{A})\end{array}$} & \multicolumn{3}{|c|}{ Nồng độ BRs (ppm) (B) } & \multirow{2}{*}{$\mathrm{TB}(\mathrm{A})$} \\
\hline & & $0(\mathrm{DC})$ & 2 & 4 & \\
\hline \multirow{5}{*}{$\begin{array}{l}\text { Chiều dài rễ } \\
(\mathrm{cm})\end{array}$} & 0 (Đối chứng) & 31,88 & 33,39 & 35,44 & $33,57^{\mathrm{a}}$ \\
\hline & 3 & 22,55 & 28,15 & 30,02 & $26,91^{\mathrm{b}}$ \\
\hline & 4 & 18,69 & 23,45 & 28,40 & $23,67^{\mathrm{c}}$ \\
\hline & $\mathrm{TB}(\mathrm{B})$ & $24,37^{\mathrm{b}}$ & $28,46^{\mathrm{ab}}$ & $31,29^{\mathrm{a}}$ & \\
\hline & \multicolumn{5}{|c|}{$\mathrm{CV}(\%)=16,16 \mathrm{~F}_{\mathrm{A}}=11,21^{* *} \mathrm{~F}_{\mathrm{B}}=5,3^{*} \mathrm{~F}_{\mathrm{AxB}}=0,41^{\mathrm{ns}}$} \\
\hline \multirow{5}{*}{$\begin{array}{c}\text { Chiều cao cây } \\
(\mathrm{cm})\end{array}$} & 0 (Đối chứng) & 95,64 & 98,01 & 97,34 & $96,00^{\mathrm{a}}$ \\
\hline & 3 & 90,92 & 92,97 & 94,03 & $92,58^{\mathrm{b}}$ \\
\hline & 4 & 87,75 & 91,75 & 93,71 & $91,07^{\mathrm{c}}$ \\
\hline & TB (B) & $91,44^{\mathrm{b}}$ & $94,17^{\mathrm{a}}$ & $95,03^{\mathrm{a}}$ & \\
\hline & \multicolumn{5}{|c|}{$\mathrm{CV}(\%)=2,26 \mathrm{~F}_{\mathrm{A}}=19,15^{* *} \mathrm{~F}_{\mathrm{B}}=7,12^{* *} \mathrm{~F}_{\mathrm{AxB}}=0,88^{\mathrm{ns}}$} \\
\hline \multirow{5}{*}{$\begin{array}{l}\text { Diện tích lá đòng } \\
\left(\mathrm{cm}^{2}\right)\end{array}$} & 0 (Đối chứng) & $38,47^{\mathrm{b}}$ & $42,41^{\mathrm{a}}$ & $44,18^{\mathrm{a}}$ & $41,68^{\mathrm{a}}$ \\
\hline & 3 & $35,28^{\mathrm{c}}$ & $36,46^{\mathrm{bc}}$ & $35,37^{\mathrm{c}}$ & $35,70^{\mathrm{c}}$ \\
\hline & 4 & $33,54^{\mathrm{c}}$ & $43,63^{\mathrm{a}}$ & $36,36^{\mathrm{c}}$ & $37,85^{\mathrm{b}}$ \\
\hline & $\mathrm{TB}(\mathrm{B})$ & $35,76^{\mathrm{b}}$ & $38,64^{\mathrm{a}}$ & $40,83^{\mathrm{a}}$ & \\
\hline & \multicolumn{5}{|c|}{$\mathrm{CV}(\%)==4,32 \mathrm{~F}_{\mathrm{A}}=29,99^{* *} \mathrm{~F}_{\mathrm{B}}=21,11^{*} \mathrm{~F}_{\mathrm{AxB}}=9,08^{*}$} \\
\hline
\end{tabular}

nhau, việc phun BRs giúp cây lúa cải thiện diện tích lá đòng. Diện tích lá đòng có giá trị cao nhất khi được phun BRs ở nồng độ 4 ppm $\left(40,83 \mathrm{~cm}^{2}\right)$ và thấp nhất khi không phun $\left(35,76 \mathrm{~cm}^{2}\right)$, chênh lệch $5,07 \mathrm{~cm}^{2}$. Bên cạnh đó, diện tích lá đòng của cây lúa dưới ảnh hưởng tương tác giữa nồng độ mặn và BRs khác biệt có ý nghĩa thống kê. Cây lúa được trồng trong điều kiện không xử lý mặn và được phun BRs ở nồng độ 4 ppm cho diện tích lá đòng cao nhất $\left(44,18 \mathrm{~cm}^{2}\right)$. Diện tích lá đòng thấp nhất khi cây lúa được trồng trong điều kiện xử lý mặn ở nồng độ $4 \%$ và không được phun BRs $\left(33,54 \mathrm{~cm}^{2}\right)$. Kết quả này cho thấy, nồng độ mặn cao làm giảm diện tích lá đòng của cây lúa và việc phun BRs giúp cây lúa thích nghi tốt với điều kiện mặn.

Chiều dài rễ của cây lúa bị ảnh hưởng bởi nồng độ mặn, BRs và tương tác giữa hai yếu tố này (Bảng 1). Cây lúa được xử lý mặn ở nồng độ càng cao thì chiều dài rễ càng ngắn (Hình 1$)$. Khi được xử lý mặn ở nồng độ $4 \%$, cây lúa có chiều dài rễ ngắn nhất $(23,67 \mathrm{~cm})$ không khác biệt thống kê so với ở nồng độ $3 \%$, nhưng khác biết rất có ý nghĩa thống kê so với đối chứng $0 \%$ o $(33,57 \mathrm{~cm})$. Chênh lệch chiều dài rễ cây lúa ở nồng độ mặn $0 \%$ và $4 \%$ là $9,90 \mathrm{~cm}$. Cây lúa được phun các nồng độ BRs khác nhau có chiều dài rễ khác biệt có ý nghĩa thống kê. Cây lúa được phun BRs ở nồng độ 4 ppm có chiều dài rễ đạt cao nhất $(31,29$ $\mathrm{cm})$ và thấp nhất ở nồng độ 0 ppm $(24,37 \mathrm{~cm})$.

Tương tác giữa nồng độ xử lý mặn và phun BRs không đến chiều dài rễ cây lúa. Chiều dài rễ lúa dao động trong khoảng 18,69 đến 31,88 cm.

Nồng độ mặn và BRs ảnh hưởng đến các yếu tố cấu thành năng suất, do đó dẫn đến sự khác biệt về năng suất của cây lúa. Khi được xử lý mặn ở nồng độ càng cao thì năng suất cây lúa càng thấp (Bảng 2). Năng suất cây lúa đạt thấp nhất khi được xử lý mặn ở nồng độ 4\%o (503,70 g/thùng) và cao nhất ở nồng độ đối chứng $0 \%$ o $(655,01$ $\mathrm{g} /$ thùng). Việc phun bổ sung BRs cho cây lúa giúp cải thiện năng suất đáng kể. Khi phun BRs ở nồng độ 2 ppm cây lúa có năng suất cao nhất (603,35 g/thùng) và thấp nhất ở nồng độ 0 ppm (521,78 $\mathrm{g} /$ thùng). Tương tác giữa nồng độ mặn và $B R s$ cũng tác động rõ rệt đến năng suất cây lúa. Cây lúa được xử lý mặn ở nồng độ $0 \%$ kết hợp với việc phun BRs ở nồng độ 2 ppm cho năng suất cao nhất, đạt 725,55 g/thùng. Trong khi đó, ở nồng độ mặn $4 \%$ và không được phun BRs, cây lúa cho năng suất thấp nhất $(420,04 \mathrm{~g} /$ thùng). Kết quả này tương tự với kết quả của Hayat \& ctv. (2007), khi tiến hành nghiên cứu trên cây cải.

Kết quả Bảng 3 cho thấy hàm lượng protein và proline trong cây lúa chịu tác động của nồng độ 

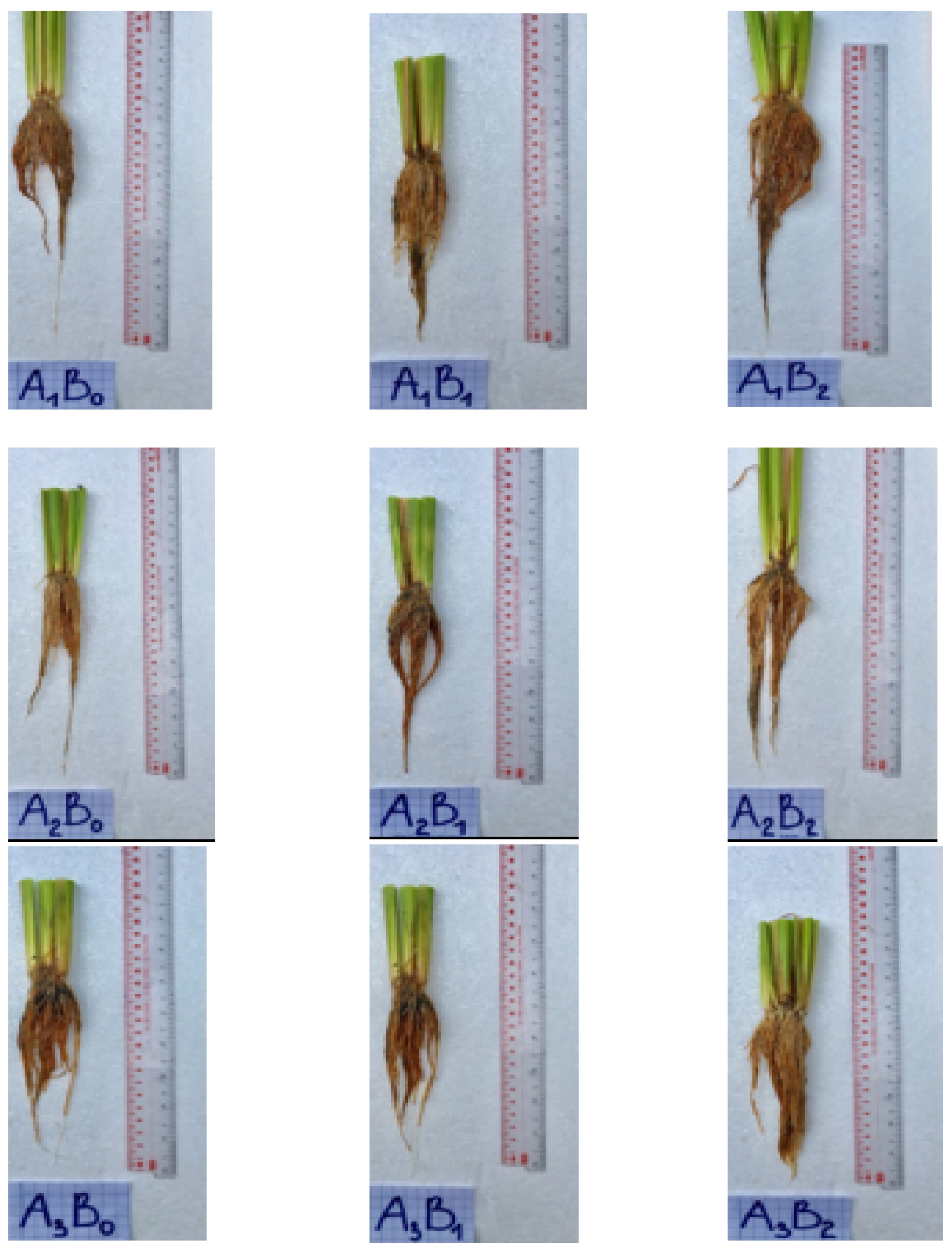

Hình 1. Chiều dài rễ lúa Jasmine 85 khi được phun BRs ở các nồng độ mặn khác nhau. Chú thích:

$\mathrm{A}_{1} \mathrm{~B}_{0}: 0 \%$ + 0 ppm; $\mathrm{A}_{1} \mathrm{~B}_{1}: 0 \%$ + 2 ppm; $\mathrm{A}_{1} \mathrm{~B}_{2}: 0 \%$ + 4 ppm.

$\mathrm{A}_{2} \mathrm{~B}_{0}: 3 \% 0+0$ ppm; $\mathrm{A}_{2} \mathrm{~B}_{1}: 3 \% 0+2 \mathrm{ppm} ; \mathrm{A}_{2} \mathrm{~B}_{2}: 3 \% 0+4 \mathrm{ppm}$.

$\mathrm{A}_{3} \mathrm{~B}_{0}: 4 \% 0+0$ ppm; $\mathrm{A}_{3} \mathrm{~B}_{1}: 4 \% 0+2 \mathrm{ppm} ; \mathrm{A}_{3} \mathrm{~B}_{2}: 4 \% 0+4 \mathrm{ppm}$. 
Bảng 2. Ảnh hưởng của Brassinosteroid (BRs) đến các yếu tố cấu thành năng suất và năng suất giống lúa Jasmine 85

\begin{tabular}{|c|c|c|c|c|c|}
\hline \multirow{2}{*}{ Chỉ tiêu } & \multirow{2}{*}{$\begin{array}{c}\text { Độ mặn }(\% 0) \\
(\mathrm{A})\end{array}$} & \multicolumn{3}{|c|}{ Nồng độ BRs (ppm) (B) } & \multirow{2}{*}{$\mathrm{TB}(\mathrm{M})$} \\
\hline & & 0 & 2 & 4 & \\
\hline \multirow{5}{*}{$\begin{array}{c}\text { Tổng số hạt trên cây } \\
\text { (hạt/cây) }\end{array}$} & 0 & 322,46 & 355,13 & 322,46 & $338,89^{\mathrm{a}}$ \\
\hline & 3 & 298,25 & 306,75 & 327,38 & $310,79^{\mathrm{b}}$ \\
\hline & 4 & 279,46 & 296,17 & 321,04 & $298,89^{c}$ \\
\hline & $\mathrm{TB}(\mathrm{B})$ & $300,06^{\mathrm{b}}$ & $319,35^{\mathrm{a}}$ & $329,17^{\mathrm{a}}$ & \\
\hline & $\mathrm{CV}(\%)=6,10$ & $\mathrm{~F}_{\mathrm{A}}=10$, & $* * \mathrm{~F}_{\mathrm{B}}=$ & $31^{*} \mathrm{~F}_{\mathrm{AxB}}$ & $=1,09^{\mathrm{ns}}$ \\
\hline \multirow{5}{*}{$\begin{array}{l}\text { Tỷ lệ hạt chắc } \\
(\%)\end{array}$} & 0 & $68,97^{\mathrm{ab}}$ & $72,20^{\mathrm{a}}$ & $69,73^{\mathrm{ab}}$ & $70,30^{\mathrm{a}}$ \\
\hline & 3 & $63,53^{\mathrm{bc}}$ & $65,07^{\mathrm{abc}}$ & $68,17^{\mathrm{abc}}$ & $65,59^{\mathrm{b}}$ \\
\hline & 4 & $55,10^{\mathrm{d}}$ & $60,93^{\mathrm{cd}}$ & $65,57^{\mathrm{abc}}$ & $60,53^{\mathrm{c}}$ \\
\hline & $\mathrm{TB}(\mathrm{B})$ & $62,53^{\mathrm{b}}$ & $66,07^{a b}$ & $67,82^{\mathrm{a}}$ & \\
\hline & $\mathrm{CV}(\%)=6,30$ & $\overline{F_{A}}=12,($ & $* * \mathrm{~F}_{\mathrm{B}}=$ & $84^{*} \mathrm{~F}_{\mathrm{AxB}}$ & $=4,25^{*}$ \\
\hline \multirow{5}{*}{$\begin{array}{l}\text { Trọng lượng } 1000 \text { hạt } \\
(\mathrm{g})\end{array}$} & 0 & $26,25^{\mathrm{b}}$ & $28,14^{\mathrm{a}}$ & $26,07^{\mathrm{b}}$ & $26,82^{\mathrm{a}}$ \\
\hline & 3 & $23,60^{\mathrm{c}}$ & $24,40^{\mathrm{c}}$ & $24,88^{\mathrm{bc}}$ & $24,29^{\mathrm{b}}$ \\
\hline & 4 & $21,84^{\mathrm{d}}$ & $23,67^{\mathrm{c}}$ & $24,53^{c}$ & $23,35^{\mathrm{c}}$ \\
\hline & $\mathrm{TB}(\mathrm{B})$ & $23,89^{b}$ & $25,41^{\mathrm{a}}$ & $25,16^{\mathrm{a}}$ & \\
\hline & $\mathrm{CV}(\%)=3,13$ & $\mathrm{~F}_{\mathrm{A}}=47,8$ & $* * \mathrm{~F}_{\mathrm{B}}=$ & $82^{* *} \mathrm{~F}_{\mathrm{AxB}}$ & $=4,13^{*}$ \\
\hline \multirow{5}{*}{$\begin{array}{l}\text { Năng suất } \\
\text { (g/thùng) }\end{array}$} & 0 & $645,76^{\mathrm{ab}}$ & $725,55^{\mathrm{a}}$ & $593,74^{\text {bc }}$ & $655,01^{\mathrm{a}}$ \\
\hline & 3 & $499,54^{\mathrm{cd}}$ & $555,81^{\mathrm{bc}}$ & $573,89^{\mathrm{bc}}$ & $543,08^{\mathrm{b}}$ \\
\hline & 4 & $420,04^{\mathrm{d}}$ & $528,68^{\mathrm{c}}$ & $562,37^{\mathrm{bc}}$ & $503,70^{\mathrm{b}}$ \\
\hline & $\mathrm{TB}(\mathrm{B})$ & $521,78^{\mathrm{b}}$ & $603,35^{\mathrm{a}}$ & $576,67^{\mathrm{ab}}$ & \\
\hline & $\mathrm{CV}(\%)=10,5$ & $\mathrm{~F}_{\mathrm{A}}=15$ & $1^{* *} \mathrm{~F}_{\mathrm{B}}=$ & $4,34^{*} \mathrm{~F}_{\mathrm{AxB}}$ & $=2,6^{* *}$ \\
\hline
\end{tabular}

Bảng 3. Ảnh hưởng của Brassinosteroid (BRs) đến các yếu tố cấu thành năng suất và năng suất giống lúa Jasmine 85

\begin{tabular}{|c|c|c|c|c|c|}
\hline \multirow{2}{*}{ Chỉ tiêu } & \multirow{2}{*}{$\begin{array}{c}\text { Độ mặn }(\% 0) \\
(\mathrm{A})\end{array}$} & \multicolumn{3}{|c|}{ Nồng độ BRs (ppm) (B) } & \multirow{2}{*}{$\mathrm{TB}(\mathrm{A})$} \\
\hline & & 0 & 2 & 4 & \\
\hline \multirow{5}{*}{$\begin{array}{c}\text { Protein } \\
(\mu \mathrm{g} / \mathrm{g} \text { TLT })\end{array}$} & 0 & $66,2^{\mathrm{e}}$ & $65,3^{\mathrm{e}}$ & $81,9^{\mathrm{a}}$ & $71,1^{\mathrm{b}}$ \\
\hline & 3 & $55,7^{\mathrm{g}}$ & $73,6^{\mathrm{d}}$ & $63,0^{\mathrm{f}}$ & $64,1^{\mathrm{c}}$ \\
\hline & 4 & $65,9^{\mathrm{e}}$ & $75,9^{\mathrm{c}}$ & $78,6^{\mathrm{b}}$ & $73,5^{\mathrm{a}}$ \\
\hline & $\mathrm{TB}(\mathrm{B})$ & $62,6^{\mathrm{c}}$ & $71,6^{\mathrm{b}}$ & $74,5^{\mathrm{a}}$ & \\
\hline & $\mathrm{CV}(\%)=1,3$ & $\mathrm{~A}=260$ & $46^{* *} \mathrm{~F}_{\mathrm{B}}$ & $=423,97$ & $\mathrm{~B}=179,11^{* *}$ \\
\hline \multirow{5}{*}{$\begin{array}{c}\text { Proline } \\
(\mu \mathrm{g} / \mathrm{mg} \text { protein })\end{array}$} & 0 & $10,91^{\mathrm{g}}$ & $11,08^{\mathrm{fg}}$ & $11,28^{\mathrm{ef}}$ & $11,09^{\mathrm{c}}$ \\
\hline & 3 & $22,08^{\mathrm{a}}$ & $13,67^{\mathrm{c}}$ & $22,83^{\mathrm{a}}$ & $19,52^{\mathrm{a}}$ \\
\hline & 4 & $18,78^{\mathrm{b}}$ & $18,92^{\mathrm{b}}$ & $13,39^{\mathrm{d}}$ & $17,03^{\mathrm{b}}$ \\
\hline & TB (B) & $17,26^{\mathrm{a}}$ & $14,56^{\mathrm{c}}$ & $15,83^{\mathrm{b}}$ & \\
\hline & $\mathrm{CV}(\%)=3,1$ & $\mathrm{~A}=12$, & $2^{* *} \mathrm{~F}_{\mathrm{B}}$ & $67,24^{* *}$ & $=187,17^{* *}$ \\
\hline
\end{tabular}

$\overline{\mathrm{a}-\mathrm{g}}$ Trong cùng 1 nhóm giá trị trung bình, các số có cùng ký tự đi kèm thể hiện sự khác biệt không có ý nghĩa thống kê.

**: khác biệt rất có ý nghĩa về mặt thống kê ở mức 0,01 .

xử lý mặn, BRs và tương tác giữa hai yếu tố này. Hàm lượng protein trong cây lúa đạt cao nhất là $73,5 \mu \mathrm{g} / \mathrm{g}$ trọng lượng tươi khi cây lúa được xử lý mặn ở nồng độ $4 \%$. Tương tự, cây lúa khi được phun BRs ở nồng độ 4 ppm cũng cho hàm lượng protein cao nhất $(74,5 \mu \mathrm{g} / \mathrm{g}$ trọng lượng tươi). Cây lúa được trồng trong điều kiện không xử lý mặn (nồng độ mặn $0 \%$ ) và được phun BRs ở nồng độ 4 ppm cho hàm lượng protein đạt cao nhất, $81,9 \mu \mathrm{g} / \mathrm{g}$ trọng lượng tươi.

Hàm lượng proline trong cây lúa cao nhất khi được xử lý mặn ở nồng độ 3\%o (đạt 19,52g/mg 
Bảng 4. Ảnh hưởng của Brassinosteroid (BRs) đến hoạt độ của hai enzyme catalase (CAT) và ascorbate peroxidase (APX) của giống lúa Jasmine 85

\begin{tabular}{|c|c|c|c|c|c|}
\hline \multirow{2}{*}{ Chỉ tiêu } & Độ mặn (\%o) & \multicolumn{3}{|c|}{ Nồng độ BRs (ppm) (B) } & \multirow{2}{*}{$\mathrm{TB}(\mathrm{A})$} \\
\hline & (A) & 0 & 2 & 4 & \\
\hline \multirow{5}{*}{$\begin{array}{c}\text { APX } \\
(\mathrm{UI} / \mathrm{mg} \text { protein })\end{array}$} & 0 & $22,08 \times 10^{-2 \mathrm{~d}}$ & $22,43 \times 10^{-2 \mathrm{~d}}$ & $11,05 \times 10^{-2 \mathrm{e}}$ & $18,52 \times 10^{-2 \mathrm{c}}$ \\
\hline & 3 & $12,08 \times 10^{-2 \mathrm{e}}$ & $38,75 \times 10^{-2 \mathrm{c}}$ & $23,40 \times 10^{-2 \mathrm{~d}}$ & $24,74 \times 10^{-2 b}$ \\
\hline & 4 & $14,88 \times 10^{-2 \mathrm{e}}$ & $76,01 \times 10^{-2 \mathrm{a}}$ & $53,18 \times 10^{-2 b}$ & $48,02 \times 10^{-2 \mathrm{a}}$ \\
\hline & TB (B) & $16,35 \times 10^{-2 \mathrm{c}}$ & $45,73 \times 10^{-2 \mathrm{a}}$ & $29,21 \times 10^{-2 b}$ & \\
\hline & $\mathrm{CV}(\%)=7,93$ & $\mathrm{~F}_{\mathrm{A}}=373,88^{* *}$ & $\mathrm{~F}_{\mathrm{B}}=335,43^{* *}$ & $\mathrm{~F}_{\mathrm{AxB}}=135,10^{*}$ & \\
\hline \multirow{3}{*}{$\begin{array}{c}\text { CAT } \\
(\mathrm{UI} / \mathrm{m} \boldsymbol{\theta} \text { protein) }\end{array}$} & 0 & $1,42^{\mathrm{e}}$ & $1,26^{\mathrm{e}}$ & $1,67^{\mathrm{d}}$ & $1,45^{\mathrm{c}}$ \\
\hline & TB (B) & $1,69^{\mathrm{c}}$ & $1,96^{\mathrm{b}}$ & $2,25^{\mathrm{a}}$ & \\
\hline & $\mathrm{CV}(\%)=3,8$ & $\mathrm{~F}_{\mathrm{A}}=385,92^{* *}$ & $\mathrm{~F}_{\mathrm{B}}=124,76^{* *}$ & $\mathrm{~F}_{\mathrm{AxB}}=84,60^{* *}$ & \\
\hline
\end{tabular}

protein) và thấp nhất ở nồng độ $0 \%$ o $(11,09$ $\mu \mathrm{g} / \mathrm{mg}$ protein), chênh lệch $8,43 \mu \mathrm{g} / \mathrm{mg}$ protein. Ở các nồng độ phun BRs khác nhau, nồng độ đối chứng $0 \mathrm{ppm}$ cho hàm lượng proline trong cây lúa cao nhất $17,26 \mu \mathrm{g} / \mathrm{mg}$ protein và thấp nhất là $14,56 \mu \mathrm{g} / \mathrm{mg}$ protein ở nồng độ $2 \mathrm{ppm}$.

Cây lúa được xử lý mặn ở nồng độ $4 \%$ o kết hợp với phun BRs ở nồng độ 0 ppm và $4 \mathrm{ppm}$ cho hàm lượng proline cao nhất (lần lượt là 22,08 và 22,83 $\mu \mathrm{g} / \mathrm{mg}$ protein). Hàm lượng proline trong cây lúa đạt thấp nhất 10,91 $\mathrm{kg} / \mathrm{mg}$ protein khi được xử lý mặn ở nồng độ $0 \%$ và không phun BRs. Theo Summart \& ctv. (2010), proline được tích lũy ở nhiều loài thực vật để đáp ứng với các stress từ môi trường như hạn hán, lạnh và mặn.

Hoạt độ enzyme catalase (CAT) và ascorbate peroxidase (APX) của giống lúa Jasmine 85 khác biệt rất có ý nghĩa thống kê dưới ảnh hưởng của nồng độ mặn, BRs và tương tác giữa hai yếu tố này (Bảng 4). Hoạt độ enzyme APX cao nhất (48,02 x $10^{2} \mathrm{UI} / \mathrm{mg}$ protein) khi cây lúa được xử lý mặn ở nồng độ $4 \%$ và thấp nhất ở nồng độ đối chứng $0 \%$ o $\left(18,52 \times 10^{-2} \mathrm{UI} / \mathrm{mg}\right.$ protein). Hoạt độ của enzyme APX cao nhất $\left(45,73 \times 10^{-2}\right.$ $\mathrm{UI} / \mathrm{mg}$ protein) khi được phun BRs ở nồng độ 2 ppm và thấp nhất ở nồng độ 0 ppm $\left(16,35 \times 10^{-2}\right.$ $\mathrm{UI} / \mathrm{mg}$ protein). Cây lúa khi được xử lý mặn ở nồng độ $4 \%$ o kết hợp phun BRs ở nồng độ 2 ppm cho kết quả hoạt độ enzyme APX cao nhất (45,73 x $10^{-2} \mathrm{UI} / \mathrm{mg}$ protein).

Kết quả Bảng 4 cũng cho thấy cây lúa khi được xử lý mặn ở nồng độ $4 \%$ có hoạt độ enzyme CAT của cây lúa đạt cao nhất (2,43 UI/mg protein), khác biệt rất có ý nghĩa thống kê so với các nồng độ còn lại trong thí nghiệm. Ở các nồng độ phun BRs khác nhau, cây lúa có hoạt độ enzyme CAT cao nhất $(2,25 \mathrm{UI} / \mathrm{mg}$ protein) khi được phun ở nồng độ 4 ppm và thấp nhất (1,69 UI/mg protein) ở nồng độ 0 ppm. Tương tác giữa nồng độ mặn $4 \%$ và $\mathrm{BRs} 2 \mathrm{ppm}$ cho kết quả hoạt độ enzyme CAT cao nhất (2,92 UI/mg protein). Theo Nunez \& ctv. (2003), cây lúa bị stress mặn và được xử lý bằng BRs cho thấy sự gia tăng đáng kể các hoạt động của CAT và tăng nhẹ APX. Bajguz (2011) cũng đã cho thấy rằng xử lý bằng Brassinolide có hiệu quả trong việc tăng hoạt động của các enzyme chống oxy hóa (CAT và APX).

\section{Kết Luận}

Cây lúa được trồng ở điều kiện xử lý mặn càng cao thì sinh trưởng và năng suất càng giảm. Phun BRs giúp cây lúa cải thiện các chỉ tiêu về sinh trưởng và năng suất trong điều kiện xử lý mặn. Khi cây lúa được xử lý mặn ở nồng độ $4 \%$ o kết hợp phun BRs ở nồng độ 2 ppm có hoạt độ enzyme $\operatorname{APX}\left(76,01 \times 10^{-2} \mathrm{UI} / \mathrm{mg}\right.$ protein $)$ và $\operatorname{CAT}(2,92$ $\mathrm{UI} / \mathrm{mg}$ protein) cao nhất giúp gia tăng khả năng chịu mặn.

\section{Tài Liệu Tham Khảo (References)}

Bajguz, A. (2011). Brassinosteroids-occurence and chemical structures in plants. In Hayat, S., and Ahmad, A. (Eds.). Brassinosteroids: a class of plant hormone (127). Berlin, Germany: Springer.

Bajguz, A., \& Hayat, S. (2009). Effects of brassinosteroids on the plant responses to environmental stresses. Plant Physiology and Biochemistry 47, 1-8.

Bradford, M. M. (1976). A rapid and sensitive method for the quantitation of microgram quantities of protein utilizing the principle of protein-dye binding. Analytical Biochemistry 72, 248-254. 
Chance, B., \& Maehly, A. C. (1955). Assay of catalases and peroxidases. Methods in Enzymology, 764-775.

Clouse, SD., \& Sasse, J. M., (1998), Brassinosteroids: essential regulators of plant growth and development. Annual Review of Plant Physiology and Plant Molecular Biology 49, 427-451.

Hasanuzzaman, M., Fujita, M., Islam, M. N., Ahamed, K. U., \& Nahar, K. (2009). Performance of four irrigated rice varieties under different levels of salinity stress. International Journal of Integrative Biology 6, 85-90.

Hayat, S., Ali, B., Hasan, S. A., \& Ahmad, A. (2007). Effect of 28-homobrassinolide on salinity-induced changes in Brassica juncea. Turkish Journal of Biology 31(3), 141-146.

Hayat, S., Hasan, S. A., Hayat, Q., \& Ahmad, A. (2010). Brassinosteroids protect Lycopersicon esculentumfrom cadmium toxicity applied as shotgun approach. Protoplasma 239, 3-14.

Nakano, Y., \& Asada, K. (1981). Hydrogen peroxide is scavenged by ascorbate peroxidase in spinach chloroplasts. Plant \& Cell Physiology 22, 867-880.

Nguyen, B. V. (2018). The study of the method of saltwater irrigation combined with nitrogen fertilization and nutritional support to improve rice growth on salt - affected soils (Unpublished doctoral dissertation). Can Tho University, Can Tho, Vietnam.
Núñez, M., Mazzafera, P., Mazorra, L. M., Siqueira, W. J., \& Zullo, M. A. T. (2003). Influence of a brassinosteroid analogue on antioxidant enzymes in rice grown in culture medium with $\mathrm{NaCl}$. Biologia Plantarum $47(1), 67-70$.

Paquin, R., \& Lechasseur, P. (1979). Observations sur une méthode de dosage de la praline libre dans les extraits de plantes. Canadian Journal of Botan 57, 1851-1854.

Saxena, M. K., \& Pandey, K. K. (1981). Physiological studies on salt tolerance of ten rice varieties. I. Growth and yield aspects. Indian Journal of Plant Physics 24, 61-68.

Summart, J., Thanonkeo, P., Panichajakul, S., Prathepha, P., \& McManus, M. T. (2010). Effect of salt stress on growth, inorganic ion and proline accumulation in Thai aromatic rice, Khao Dawk. African Journal of Biotechnology 9(2), 145-152. 